\title{
AVALIAÇÃO DOS SERVIÇOS ECOSSISTÊMICOS OFERECIDOS PELAS PRAIAS DO MUNICÍPIO DE CAUCAIA, CEARÁ, BRASIL
}

\author{
Antônio Emanuel dos Santos Silva ${ }^{(a)}$, Davis Pereira de Paula ${ }^{(b)}$ \\ (a) Centro de Ciências e Tecnologia, Universidade Estadual do Ceará, antonioemanuel2912@gmail.com \\ (b) Centro de Ciências e Tecnologia, Universidade Estadual do Ceará, davis.paula@uece.br
}

\section{Eixo: DINÂMICA E GESTÃO DE ZONAS COSTEIRAS}

\begin{abstract}
Resumo
As praias ofertam diversos serviços ecossistêmicos que podem auxiliar no desenvolvimento socioeconômico de comunidades praianas. É necessário realizar uma valoração qualitativa desses serviços oferecidos, pois esses estudos servem como subsídios para um melhor planejamento dessas áreas de intenso dinamismo e que concentram índices elevados de urbanização. Nesta pesquisa evidenciou-se cinco parâmetros avaliativos, são eles, os serviços de suporte e regulação, provisão, informação e cultura, determinados por valores qualiquantitativos, atribuindo valores ausente/baixo (1), médio (2), alto (3). Foram identificados três setores de praia com características homogêneas ao longo do litoral, um setor mais antropizado, com artificialização da costa, um outro transitivo, que possui ambientes de amenidades como dunas, lagunas e faixas de praias mais largas, e o último caracterizado por ter seus ecossistemas mais preservados em comparação às demais praias do município, oferecendo assim serviços mais qualificados para os usuários.
\end{abstract}

Palavras chave: Serviços ecossistêmicos, geoambientes, litoral e praias

\section{Introdução}

Os recursos naturais provenientes dos ecossistemas litorâneos são muitas vezes a base para a economia local, regional e internacional, principalmente quando tratamos de praias, um geoambiente extremamente dinâmico e que oferece os mais diversos serviços ecossistêmicos, de modo que o seu uso indiscriminado pode reduzir de maneira significativa a sua capacidade de recarga e resiliência.

A importância da perda de serviços ecossistêmicos não recai apenas sobre a economia de base ou global, mas sim sobre o bem-estar humano. De acordo com o relatório do TEEB (2010), os serviços ecossistêmicos estão ligados diretamente aos benefícios oferecidos pela natureza, sejam eles: alimentação, matérias-primas, medicamentos e recursos hídricos. Além disso, os sistemas naturais regulam o clima, a oferta de alimentos e a produção de matéria e energia.

Deste modo, discutir a importância dos serviços ecossistêmicos para sociedade é inevitável, especialmente no que concerne a gestão integrada dos geoambientes. Assim, o objetivo deste estudo 
XVII Simpósio Brasileiro de Geografia Física Aplicada

I Congresso Nacional de Geografia Física
OS DESAFIOS DA GEOGRAFIA FÍSICA NA FRONTEIRA DO CONHECIMENTO

Instituto de Geociências - Unicamp

Campinas - SP

28 de Junho à 02 de Julho de 2017

é realizar uma valoração qualitativa dos serviços ecossistêmicos intrínsecos as praias do litoral de Caucaia, inserida na Região Metropolitana de Fortaleza - CE, no Estado do Ceará.

\section{Materiais, métodos e técnicas utilizadas}

Em Caucaia, ao longo de quase $30 \mathrm{~km}$ de litoral, foram identificadas sete praias principais - Dois Coqueiros, Iparana, Pacheco, Icaraí, Tabuba, Cumbuco e Cauípe (Figura 1) - em que foram realizadas vistas de campo para identificação e descrição dos serviços ecossistêmicos. As informações foram integradas ao material geocartográfico em ambiente do Sistema de Informação Geográfica - SIG. Também foram realizadas consultas bibliográficas para auxiliar na caracterização desses ambientes e seus ecossistemas.

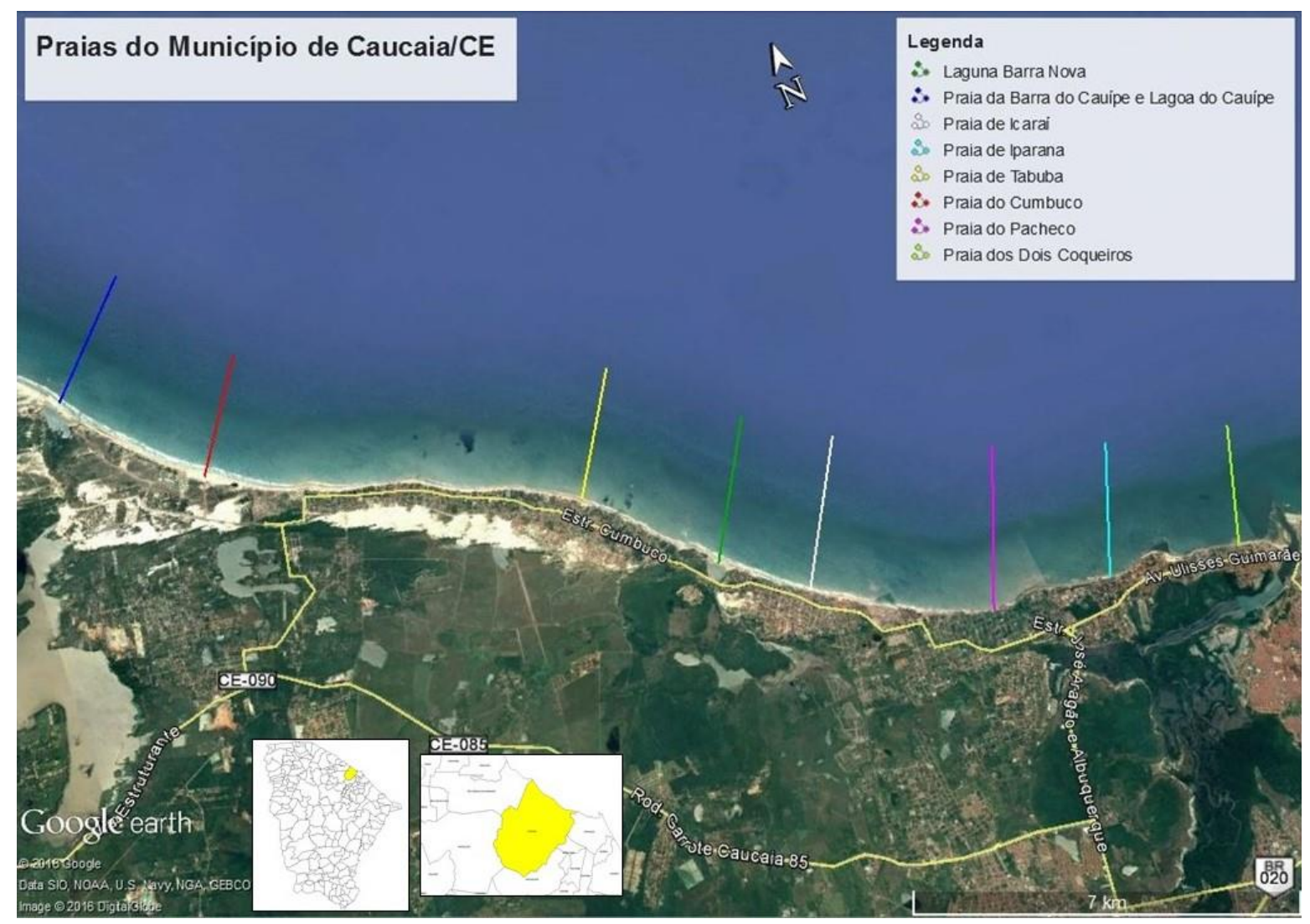

Figura 1- Segmentação utilizada para as praias do município de Caucaia- (Fonte: Google Earth Pro, 2016).

Em termos de delimitação espacial para análise dos serviços ecossistêmicos, optou-se por uma observação de uma faixa de $800 \mathrm{~m}$, contados a partir da cota batimétrica de $-6 \mathrm{~m}$ e limitando-se, continentalmente, ao limite do campo dunas móveis, conforme proposto por LIMA et al. (2016). 
Para uma análise mais completa adotou-se a valoração qualitativa dos serviços ecossistêmicos oferecidos pelas praias do Município de Caucaia, elaborado com base na metodologia aplicada na Avaliação Ecossistêmica do Milênio (MA, 2003), formulada entre 2001 e 2005. Com base nesse estudo, os serviços ecossistêmicos foram classificados em serviços de regulação, serviços de provisão (ou de abastecimento), serviços de suporte e serviços culturais.

Nesta pesquisa, optou-se por uma avaliação conjunta dos serviços de regulação e suporte, já que estão empiricamente integrados. Assim, para as praias estudadas e seus ecossistemas associados, os serviços ecossistêmicos foram agrupados em: I) Serviços de regulação e/ou suporte: incluem os serviços de retenção natural de sedimentos, recarga de aquíferos, controle e estocagem de água, assimilação e reciclagem de poluentes, dissipação da energia das ondas, proteção natural na zona de ante- praia, dentre outros; II) Serviços de provisão: incluem os serviços de produção natural de alimentos, produção de alimentos em áreas cultivadas, recursos hídricos, recursos ornamentais e recursos genéticos/medicinais; III) Serviços de informação e cultura: incluem os serviços de ecoturismo, turismo cultural e/ou histórico, recreação e lazer, e atratividade cênica. As características adotadas nesta valoração quali-quantitativa, sendo que a cada serviço, ou ausência deste, é atribuída a qualificação de baixo (valor 1), médio (valor 2) ou alto (valor 3) (SANTOS e SILVA, 2012).

\section{Resultados e discussões}

O litoral do município de Caucaia encontra-se massivamente ocupado por casas de veraneio, condomínios fechados e equipamentos turísticos. A sua linha de costa encontra-se artificializada por equipamentos urbanos, que comprometem a estabilidade dos ambientes e consequentemente, o desenvolvimento dos serviços ecossistêmicos. A tabela I apresenta os resultados da valoração qualiquantitativa das sete praias do litoral de Caucaia. A Praia da Barra do Cauipe apresentou o maior escore dentre todas as demais, chegando ao total de 48, enquanto que a Praia do Icaraí apresentou o menor valor, 30 escores. 
Tabela I - Valores associados aos serviços ecossistêmicos oferecidos pelas praias do município de Caucaia. (Adaptado de SANTOS e SILVA, 2012).

\begin{tabular}{|c|c|c|c|c|c|c|c|}
\hline SERVIÇOS DE REGULAÇÃO E/OU SUPORTE & PBC & PC & PT & PI & PP & PIP & PDC \\
\hline Retenção Natural de Sedimentos & 3 & 3 & 2 & 2 & 2 & 2 & 2 \\
\hline Recarga de Aquíferos & 3 & 3 & 2 & 2 & 2 & 2 & 2 \\
\hline Controle e Estocagem de Água & 2 & 2 & 1 & 2 & 1 & 2 & 3 \\
\hline Assimilação e Reciclagem de Poluentes & 2 & 2 & 1 & 1 & 1 & 2 & 3 \\
\hline Dissipação da Energia das Ondas & 2 & 2 & 2 & 2 & 2 & 2 & 2 \\
\hline Proteção Natural na Zona de Ante-praia & 2 & 2 & 2 & 3 & 2 & 2 & 2 \\
\hline Proteção Natural na Zona de Pós-praia & 3 & 3 & 3 & 2 & 2 & 2 & 2 \\
\hline Refúgio e/ou Berçário Marinho & 3 & 2 & 1 & 1 & 1 & 1 & 2 \\
\hline Refúgio e/ou Berçário Terrestre ou Transicional & 3 & 2 & 2 & 1 & 1 & 1 & 2 \\
\hline SERVIÇOS DE PROVISÃO & PBC & PC & PT & PI & PP & PIP & PDC \\
\hline Produção Natural de Alimentos & 3 & 2 & 2 & 2 & 2 & 2 & 3 \\
\hline Produção de Alimentos em Áreas Cultivadas & 3 & 2 & 2 & 1 & 2 & 2 & 3 \\
\hline Recursos Hídricos & 3 & 3 & 2 & 2 & 2 & 2 & 2 \\
\hline Recursos Ornamentais & 3 & 3 & 3 & 2 & 3 & 3 & 3 \\
\hline Recursos Medicinais & 2 & 2 & 2 & 1 & 2 & 2 & 2 \\
\hline SERVIÇOS DE INFORMAÇÃO E CULTURA & PBC & PC & PT & PI & PP & PIP & PDC \\
\hline Ecoturismo & 3 & 3 & 2 & 2 & 2 & 2 & 3 \\
\hline Turismo Histórico/Cultural & 2 & 2 & 2 & 2 & 2 & 2 & 2 \\
\hline Recreação e Lazer & 3 & 3 & 2 & 1 & 1 & 2 & 2 \\
\hline Atratividade Cênica & 3 & 3 & 2 & 1 & 2 & 2 & 2 \\
\hline TOTAL & 48 & 44 & 35 & 30 & 32 & 35 & 42 \\
\hline
\end{tabular}

Obs.: PBC-Praia da Barra do Cauípe; PC-Praia do Cumbuco; PT-Praia da Tabuba; PI-Praia do Icaraí; PP-Praia do Pacheco; PIP-Praia de Iparana e PDC-Praia de Dois Coqueiros.

O litoral leste de Caucaia é composto pelas praias de Dois Coqueiros, Iparana, Pacheco e Icaraí, onde há uma ocupação urbana mais acentuada próximo ao litoral. Neste trecho foi obtido os menores valores dos serviços ecossistêmicos, de um modo geral, muito por conta da apropriação insustentável dos espaços costeiros, acarretando diversos problemas ambientais, dentre eles a erosão costeira.

Em uma faixa de transição para o setor oeste, os serviços ecossistêmicos estão mais conservados, especialmente nas adjacências da laguna do rio Barra Nova, onde a boa qualidade ambiental é aproveitada para o desenvolvimento de esportes náuticos (e.g. Kitesurf), isto é, recreação e lazer. Outros serviços destacados são os de controle e estocagem de água e produção natural de alimentos. O setor oeste do litoral de Caucaia é formado pelas praias de Tabuba, Cumbuco e Cauípe, onde foram verificadas as maiores ofertas de serviços ambientais, amenidades nas ocupações imobiliárias e serviços Culturais mais diversos, e com qualidade superior aos demais setores do litoral.

O trecho costeiro correspondente a Praia do Cumbuco é destaque quanto à prestação de serviços de recreação, lazer e atratividades cênicas (e.g. as dunas costeiras) e pela ocupação imobiliária mais valorizada do litoral caucaiense.

No extremo oeste do litoral do município encontra-se a praia da Barra do Cauípe, onde foram identificados os maiores valores dentre todas as praias investigadas nessa pesquisa, destaque em 
todos os tipos de serviços, seja por ser uma área ainda pouco alterada antropicamente, ou também por deter ecossistemas favoráveis ao bem-estar humano e natural.

\section{Considerações finais}

Em uma análise qualitativa e integral dos dados obtidos, verificou-se espacialmente que altas taxas de urbanização interferem diretamente na oferta de serviços ecossistêmicos para a comunidade que ali reside, e que se utilizam direta ou indiretamente dos serviços ecossistêmicos prestados. O litoral de Caucaia encontra-se vulnerável em áreas onde não há capacidade de resiliência dos ecossistemas costeiros que dividem o mesmo espaço com diversos equipamentos urbanos. Diante da realidade apresentada nesta pesquisa, há necessidade de se planejar racionalmente o uso e ocupação do litoral, fundamentado por pesquisas que contemplem a realidade local/municipal, fazendo um levantamento dos ecossistemas mais relevantes e de interesse social paralelo á salubridade ambiental de cada ecossistema.

\section{Agradecimentos}

Os autores agradecem à FUNCAP pela bolsa de iniciação científica. Ao CNPq pelo financiamento do projeto "Impactos costeiros no litoral de Caucaia (Ceará, Brasil) induzidos pelas obras costeiras construídas a sotamar e pelas ressacas do mar (Processo: 483811/2013-0). Ao laboratório de Geologia e Geomorfologia Costeira e Oceânica da UECE, pela infraestrutura e apoio na realização do trabalho.

\section{REFERÊNCIAS}

ANDRADE, D.C.; ROMEIRO, A.R. Serviços ecossistêmicos e sua importância para o sistema econômico e o bem-estar humano. Campinas: IE/UNICAMP, 155 p., 2009.

IPECE - Instituto de Pesquisa e Estratégia Econômica do Ceará. 2010. Perfil Básico Municipal de Caucaia. Disponível na internet: www.ipece.ce.gov.br. Acessado dia 07/12/2016.

LIMA et al. Avaliação dos Serviços Ecossistêmicos nas praias dos municípios de Fortaleza e Caucaia, Ceará, Brasil. Anais do GIAL, 2016.

MEA - MILLENNIUM ECOSYSTEM ASSESSMENT. Ecosystem and Human Well-Being: a framework for assessment. Washington, DC: Island Press. 2003.

SANTOS, Rodrigo C.; SILVA, Iracema R. Serviços ecossistêmicos oferecidos pelas praias do município de Camaçari, litoral norte do estado da Bahia, Brasil. Cadernos de Geociências, Salvador, v. 9, n. 1, p. 47 - 56, maio 2012.

TEEB - A Economia dos Ecossistemas e da Biodiversidade para Formuladores de Políticas Locais e Regionais (2010). Disponível na internet: http://www.mma.gov.br/publicacoes/biodiversidade/category/143economia-dos-ecossistemas-e-da-biodiversidade. Acessado em: 19/01/2016. 